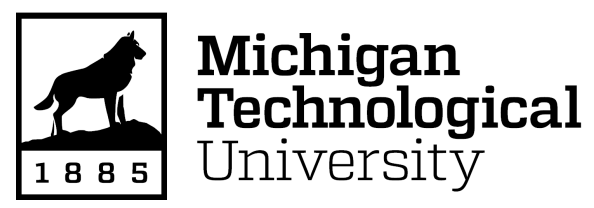

Michigan Technological University Digital Commons @ Michigan Tech

\title{
Ecological Studies of Wolves on Isle Royale Annual Report 2020-2021
}

John A. Vucetich

Michigan Technological University, javuceti@mtu.edu

Rolf O. Peterson

Michigan Technological University, ropeters@mtu.edu

Sarah R. Hoy

Michigan Technological University, srhoy@mtu.edu

Follow this and additional works at: https://digitalcommons.mtu.edu/wolf-annualreports

Part of the Animal Sciences Commons, Biodiversity Commons, Ecology and Evolutionary Biology Commons, and the Forest Sciences Commons

\section{Recommended Citation}

Vucetich, John A.; Peterson, Rolf O.; and Hoy, Sarah R., "Ecological Studies of Wolves on Isle Royale Annual Report 2020-2021" (2021). Ecological Studies of Wolves on Isle Royale. 1.

https://doi.org/10.37099/mtu.dc.wolf-annualreports/2020-2021

Follow this and additional works at: https://digitalcommons.mtu.edu/wolf-annualreports

Part of the Animal Sciences Commons, Biodiversity Commons, Ecology and Evolutionary Biology Commons, and the Forest Sciences Commons 

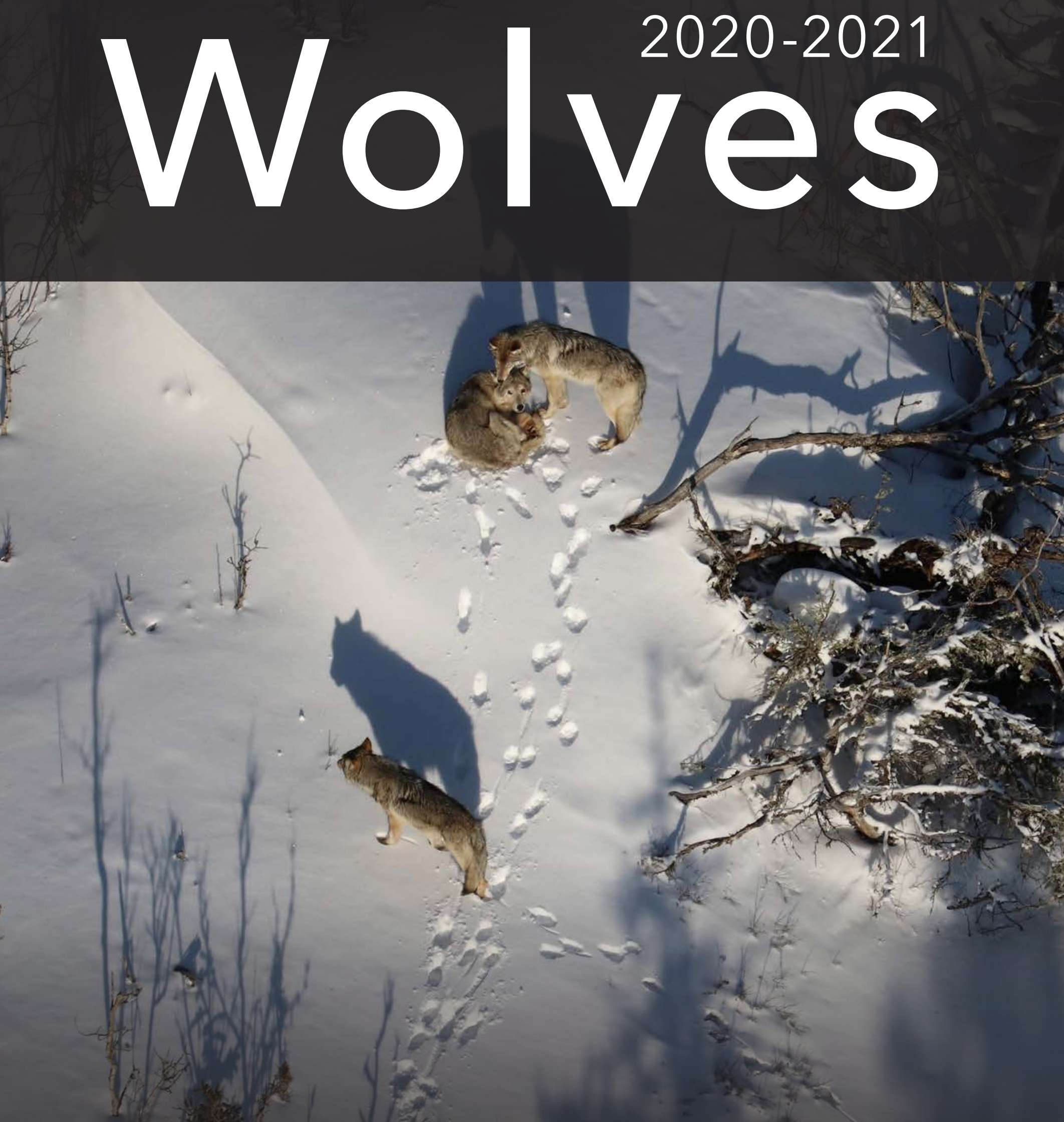

Ecological Studies of Wolves on Isle Royale 


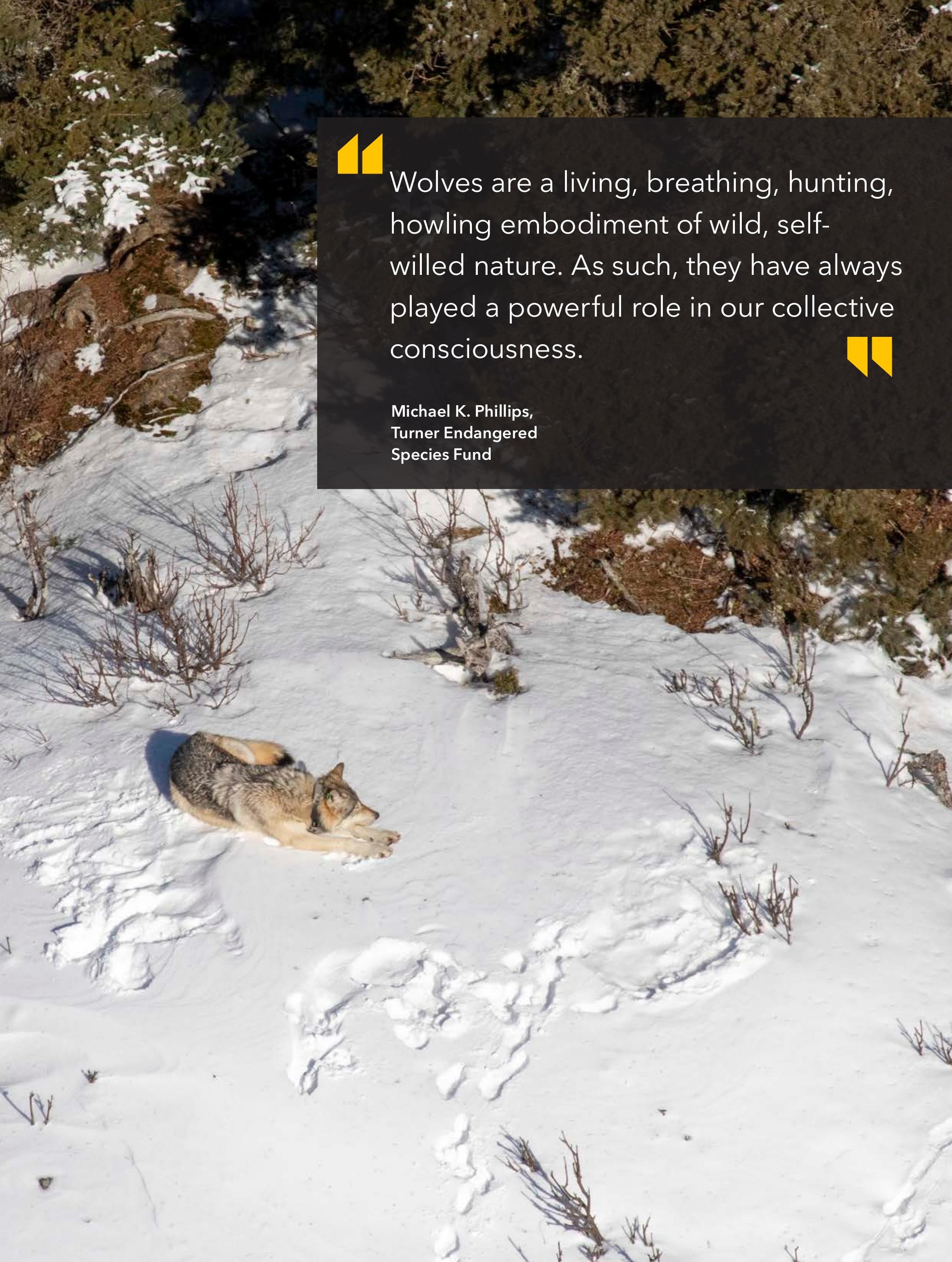




\title{
Ecological Studies of Wolves on Isle Royale
}

Annual Report 2020-2021

by

\author{
John A. Vucetich, Rolf O. Peterson, and Sarah R. Hoy \\ College of Forest Resources and Environmental Science, \\ Michigan Technological University, \\ Houghton, Michigan USA 49931-1295
}

March 2021

Front cover photograph: In February 2020, two uncollared wolves were seen in the company of a collared female (bedded) that was translocated by the National Park Service to Isle Royale from Michipicoten Island in eastern Lake Superior.

Inside front cover photograph: In March 2020, wolf 11F slept soundly on Thompson Island, a safe refuge away from the territorial imperatives of wolves on the main island. 



\title{
Support and Contributions
}

During the past year, major support for these studies was received from the National Science Foundation (DEB-1939399), National Park Service (CESU Task Agreement No. P16AC00004), a Mclntire-Stennis Grant (USDA-Nifa \#1014575), Robert Bateman Endowment at the Michigan Tech Fund, James L. Bigley Revocable Trust, and the Detroit Zoological Society.

For the period, 1 March 2020 through 28 February 2021, additional contributions were received from the following organizations and individuals: Carol A. Argentati, Dianne W. Ashley, Karen A. Bacula, David A. Beck, Dorthey L. Behrend, Leigh Beith, James Bielecki, Jerry and Jennifer Boeckman, Bob J. Bollinger, Joseph V. Brazie, Sheri A. Buller, John C. Bumby, Zan Ceeley and Laura Christensen, Alison J. Clarke, James Clink, Donald C. Close, Will Conrardy, C.B. Deligianis and Sons LLC, Peter and Amber Dohrenwend, Madeleine Dugan, Ronald and Barbara Eckoff, Mary C. Edgar, Scott and Karen Erba, Joanne Ernst, Fidelity Charitable Gift Fund, Marjorie H. Freeman, Larry Fuerst and Suzanne Scott, C. Michael and K.A. George, Edith N. Greene, Heather Greenwald, Randolf A. Gschwind, Beverly Hamilton, Steven and Lila Hammer, John and Heidi Harlander, Lana Hasper, Donald and Mary Heaton, Jeanne Heidtke, John H. Heidtke, Mary Hoddy, Roddie Larsen, Emily Loeb, Dana and Donna Lowell, Annette Matzen, Paul S. Mueller, Richard and Beatrice Ann Murray, Mary Ochsenschlager, Michael and Kari Palmer, Janet L. Parker, Mary G. Peters, Rolf and Carolyn Peterson, Judy Phillips, Joseph and Nancy Plumbo, Ronald and Julie Porritt, Jay Richardson, Robert and Darcy Rutkowski, Timothy Sanford, Michael and Nancy Savat, John and Linda Schakenbach, Joan Silaco, Laura M. Slavsky, Cay N. Strother, Russell and Barbara Tabbert, Richard and Deborah Thiel, Deke

Weaver, Paul and Emily Weber, April L. Willbur, Albert and Frances Wilson, and Kristina Yonkers.

Ken Vrana of the Isle Royale Institute has been of critical value for helping us organize our Moosewatch research expeditions. After cancellation of these activities in 2020 because of COVID-19 issues, a full expedition calendar is planned for 2021.

To learn more about how you can join one of our research expeditions, visit isleroyalewolf.org and click "Contribute \& Participate." Tax-deductible donations to support continuing research on Isle Royale wolves and moose can be sent to Wolf-Moose Study, Michigan Tech Fund, Michigan Technological University, 1400 Townsend Drive, Houghton, Michigan 49931-1295. Thank you to all who help!

Results reported here are preliminary and, in some cases, represent findings of collaborators; please do not cite without consulting the authors. The views expressed here do not necessarily reflect those of the U.S. National Park Service or the U.S. National Science Foundation. Unless otherwise indicated, all photographs were taken by one of the authors of this report.

\author{
isleroyalewolf.org
}

(P) Wolves and Moose of Isle Royale 


\section{Ecological Studies of Wolves on Isle Royale}

\section{SUMMARY OF FIELD OPERATIONS}

The COVID-19 pandemic caused significant disruption of field operations over the past year. The summer field crew was limited to Rolf and Carolyn Peterson, Isabella Evavold, Eli Paulen, Rachel Christiansen, and Amelia Evavold. Field efforts did not begin until 30 June. Most of the crew focused on a five-week effort to assess rates at which moose browse balsam fir. They measured balsam fir at sites used by GPS-collared moose during the previous winter (34 sites at the east end of Isle Royale and 35 sites at the west end). That assessment is a key component of our long-term effort to understand moose foraging behavior and its relationship to the wolves and forest of Isle Royale.

The Petersons also surveyed tagged balsam fir trees and saplings near Windigo and spent three weeks circumnavigating the island by canoe. The purpose of that trip was to discover and necropsy the remains of wolf-killed moose. They examined the remains of 29 moose, including two radio-collared moose that died in May and June. One is believed to have died from complications while giving birth. The other seems to have died from malnutrition after a stick got lodged in the animal's upper palate (Fig. 1). The Petersons remained on the island until 22 October.
Pilot Don Murray of UpNorth Aerials flew surveys to download data from collared moose in early July and late August. That effort was aided by Jill Podominick Murray. Don Murray and Rolf Peterson conducted a complete aerial count of active beaver sites during 9-15 October.

The pandemic resulted in the complete cancellation of the summer 2020 Moosewatch expeditions, which are a citizen-science program whose focus is the discovery and necropsying of wolf-killed moose.

The pandemic also resulted in the complete cancellation of the 2021 winter study, which would have resulted in estimates of abundance for the wolf and moose populations, estimates of kill rate and predation rate, and the placement of GPS collars on moose. Never before in its 63-year history had the winter study been canceled.

In the upcoming year, beginning in May 2021, we are prepared to make up as much of the lost field effort as possible, including fully operational teams of student interns, Moosewatch, and winter study.

The remainder of this annual report is a summary of several more specific research projects that we've been working on over the past year.
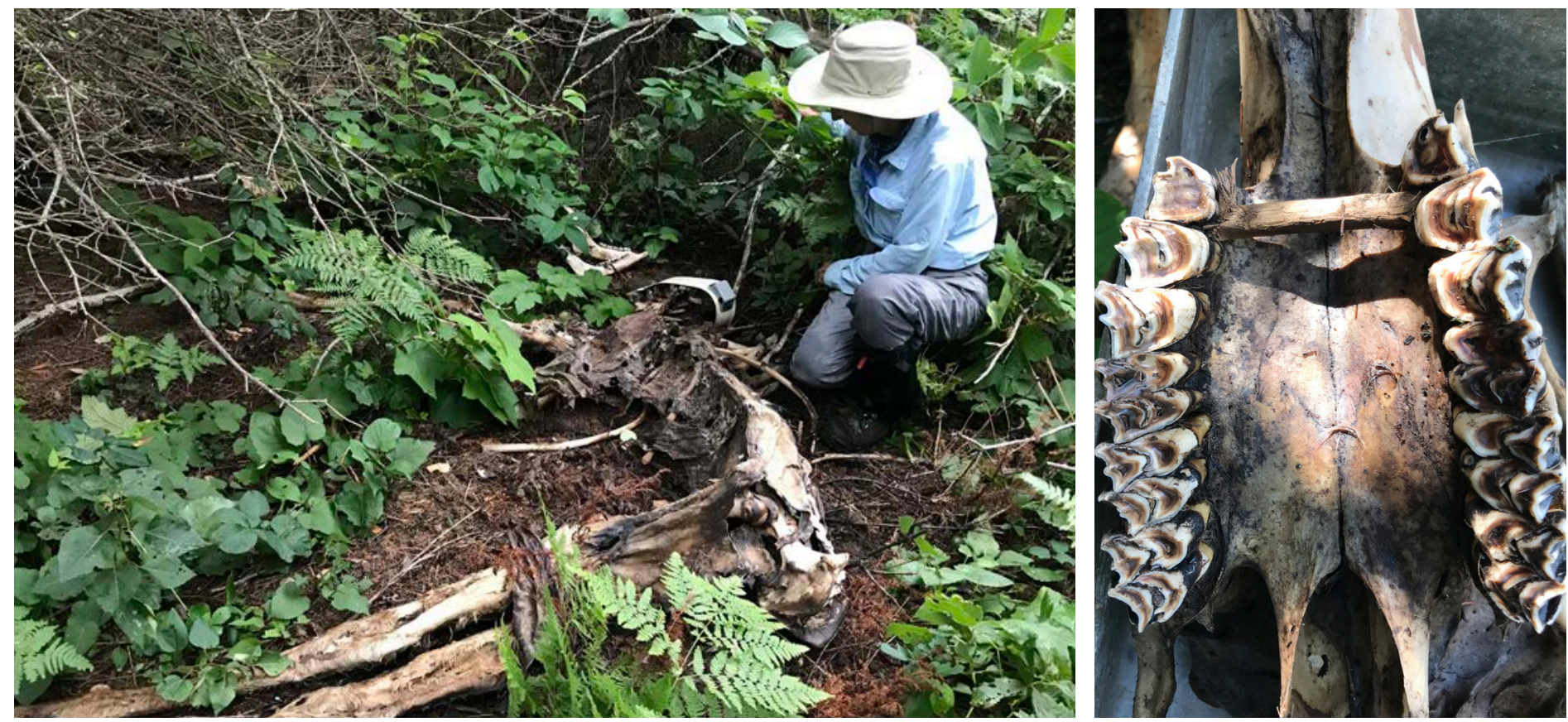

Fig. 1 This radio-collared bull (left) died in early June 2020, apparently of malnutrition. The Petersons arrived at the site in August and found (right) that the moose had been plagued by a stick that became lodged in the upper palate, which would have interfered with normal chewing and rumination. This is \#5371 in our necropsy series. 


\section{WORLD'S LARGEST COLLECTION OF MOOSE BONES}

One of the most basic activities when studying wolf-prey relationships is to necropsy the remains of wolf-killed prey. The first necropsy ever performed as part of the Isle Royale wolf-moose project took place on 8 February 1959 on a hillside rising from the north shore of Tobin Harbor. Wolves had killed the female moose about three days earlier. In the course of conducting the necropsy, Dave Mech collected a mandible (jawbone). Over the next five weeks he collected another dozen. And, a dozen more in the summer that followed. After a few years he and his mentor, Durward Al-

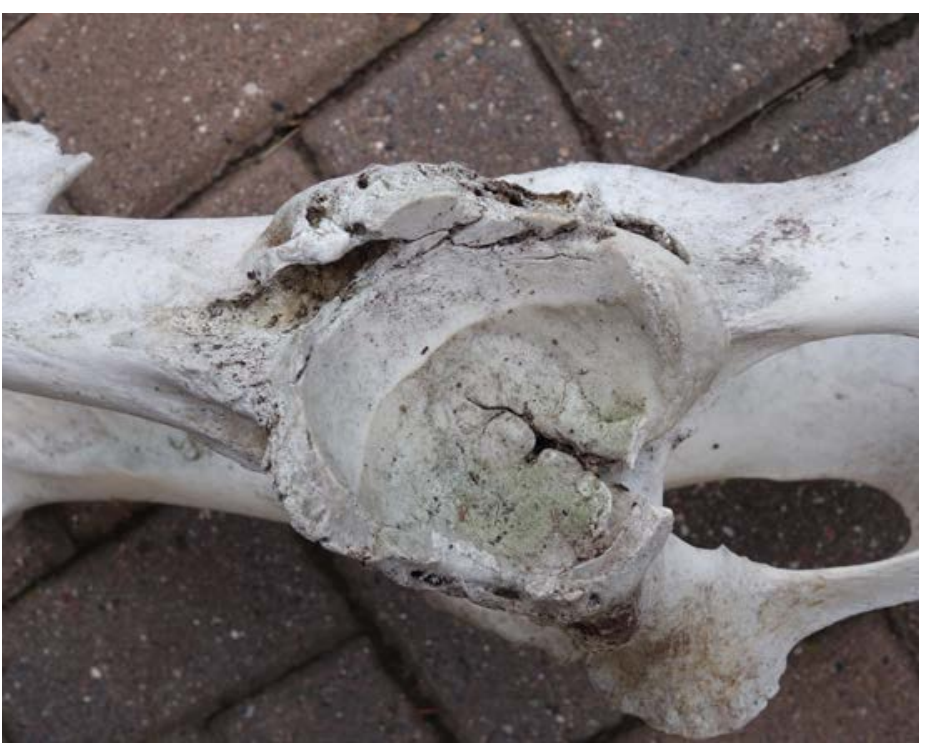

Fig. 2 Old moose on Isle Royale are often afflicted by osteoarthritis in their hips and spine. Shown here is an arthritic hip socket where the cartilage has deteriorated and the boneon-bone hip joint has migrated dorsally.

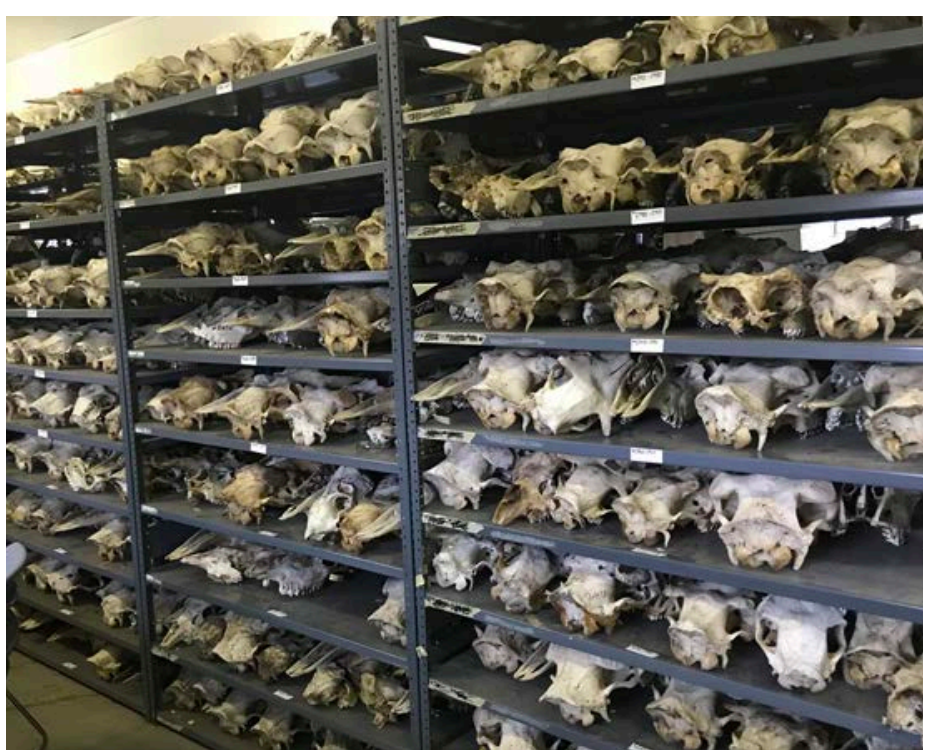

Fig. 3 Moose skulls from Isle Royale have been collected for scientific research for many decades, providing an irreplaceable archive of the environment and characteristics of individual moose from a naturally regulated population. len, had mandibles from about 100 moose. They used the mandible to infer that wolves are more likely to kill moose with "jaw necrosis" than moose without. They also used the extent of wear in the teeth to estimate approximate age, from which they inferred that wolves are more likely to kill calves or old moose, as opposed to prime-aged moose.

While those early inferences by Mech and Allen represented important advances in insight, confidence in those inferences would require the collection of more specimens. By 1970, Allen had overseen the collection of mandibles from nearly 500 moose.

In 1970, Rolf Peterson began working on the project as a graduate student to test ideas about how wolf-moose dynamics might be affected by the size of moose. The basis for that research was knowing that Isle Royale wolves kill large, dangerous prey and believing that wolves might benefit from focusing on the killing of smaller individuals. No one knew for certain at the time, but the size of moose was presumed to vary over time, from one cohort of moose to the next. For example, it seemed plausible that moose would be smaller when born during a year when moose density was high, during which nutritional stress might be greater due to competition for forage. It also seemed plausible that moose born just after a severe winter might be smaller, due to the nutritional stress of severe winters on pregnant moose. Testing those ideas would require a means for quantifying the size of moose. Important information about size is calcified in the skull and metatarsus, sometimes called the hindfoot bone (for more on the insights calcified into this bone, keep reading).

During the 1970s, Peterson also noticed what seemed to be an increase in the frequency of moose with severe arthritis in their hips and sacrum (Fig. 2). That observation led to an expansion of research protocols to include the collection of mandibles, skulls, a metatarsus, and any abnormally shaped bone. It takes more than a few specimens to test these ideas. With the turn of the century, the collection had grown to represent more than 3,000 moose (Fig. 3). By 2010, the collection had grown large enough for us to document temporal fluctuations in the incidence of arthritis and its connection to nutritional stress early in life [1]. That work is cited by those researching arthritis in humans, because the relationships are likely important for understanding human arthritis, but difficult to study in humans. It would have been impossible for anyone to have anticipated the wide-ranging values of this collection of moose bones. By 2009, the collection had grown large enough to evaluate and demonstrate how the concentration of mercury and lead in the teeth of moose declined after passage of the Clean Air Act (1970) and Clean Water Act (1972) [2]. That demonstration is significant for showing the effective 


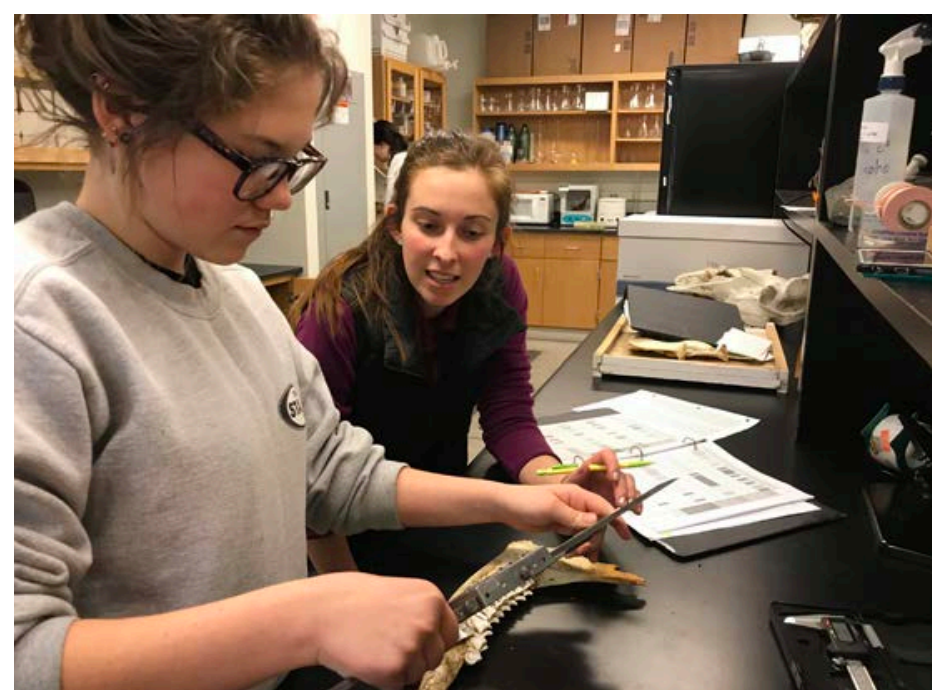

Fig. 4 Student researchers Rachel Christensen and Cheyanne Boucher at Michigan Technological University prepare a moose mandible for long-term archiving in a National Park Service repository.

ness of the antipollution regulations. By 2018, the collection had become large enough to demonstrate an association between climate warming and declines in the size of moose skulls [3]. Later in this annual report you can read about the two most recent research findings that depend on insights from this collection.

The value of these specimens is not limited to advances in scientific knowledge. The collection has also been of great value for educating the public and park visitors about moose, wolves, and the natural history of Isle Royale. Even the act of collecting these specimens has been of great value for building scientific literacy among the public. Since the late 1980s, about a third of all these bones have been collected by volunteers participating in a citizen-science program like no other. The program involves dozens of volunteers each year-many of them high school teachers-working in teams, hiking cross-country for a week at a time to discover and necropsy the remains of wolf-killed moose.

To date, we have collected more than 20,000 individual bones from more than 5,000 moose. This is, and probably will forever be, the largest collection of moose bones in the world.

As the scientific value of the collection has increased over time, so too has the need to better curate these specimens in a manner that matches their value. Throughout the history of the wolf-moose project, we have been able to stabilize the integrity of these skeletal materials to ensure their long-term preservation. But it takes a more concerted effort to provide state-of-the-art curation. To this end, we have been collaborating with the U.S. National Park Service (NPS) in a major project, which includes further cleaning of the bones, further labelling of the bones, boxed storage for the specimens to facilitate more efficient access to each specimen, photo documentation, and electronic doc-

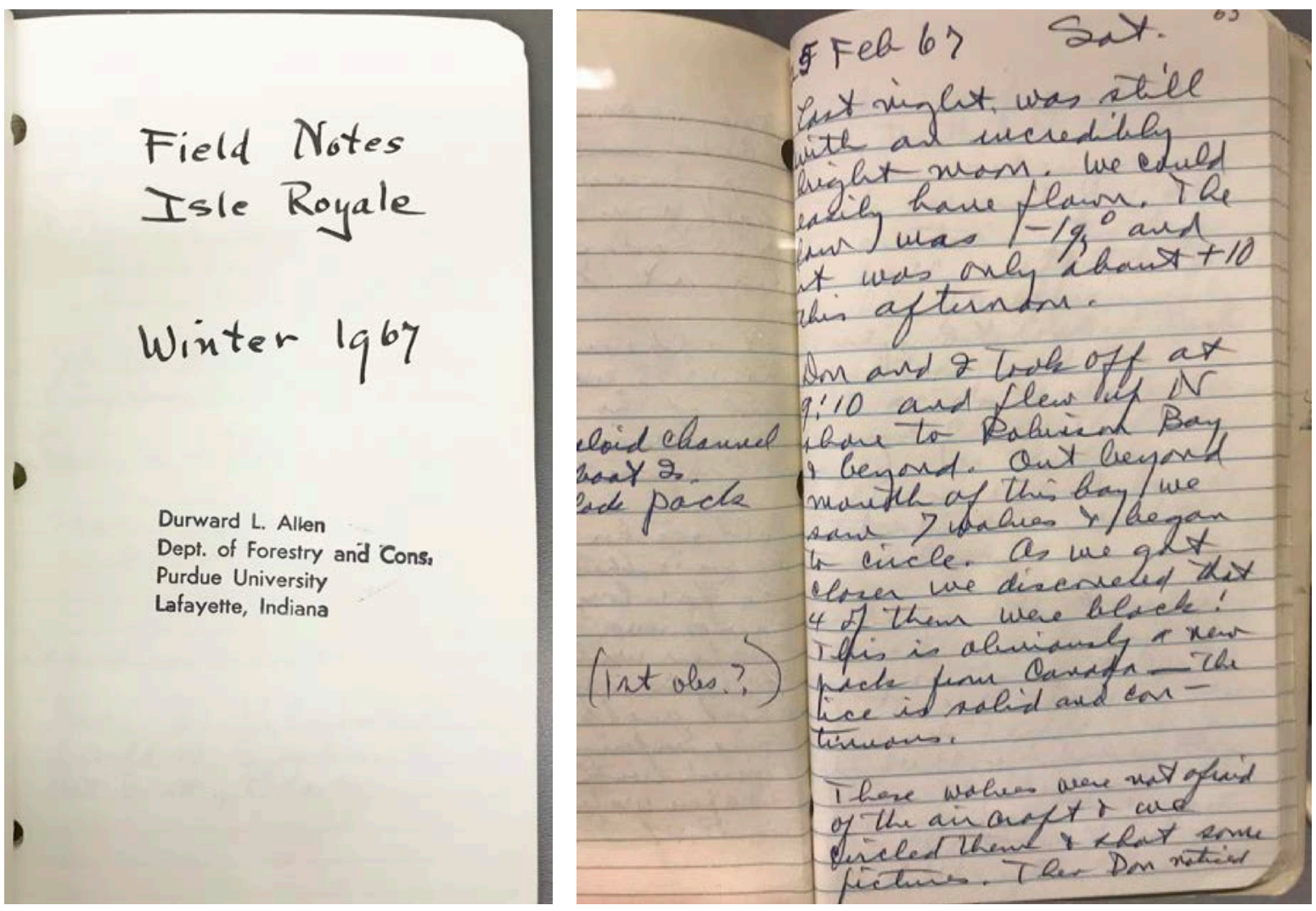

Fig. 5 Field notes of Durward L. Allen, founder of the Isle Royale wolf-moose project, record the observation (right) of black wolves immigrating to Isle Royale in 1967. These are among the many documents preserved at the Michigan Technological University Archives and Historical Collections. 
umentation in a national database of biological specimens maintained by the NPS (Fig. 4). Plans are also well under way for a new storage facility with state-of-the-art climate control, fire protection, and security.

The NPS curates not only biological specimens, but also materials of cultural value. Because the wolf-moose project began more than six decades ago, it is associated with a number of historical documents of cultural value, including handwritten field notes and researchers' correspondences (Fig. 5). These historical documents have been valuable, for example, to better understand how wolves colonized Isle Royale in the 1950s [4], for documenting the likelihood of wolves immigrating to Isle Royale from the mainland at various points in the history of the wolf population [5], and for documenting the historical presence of various mammals on Isle Royale, such as pine marten and river otter, plus sharp-tailed grouse.

Several years ago, we collaborated with staff from the MTU Archives and Historical Collections to preserve and archive these documents (Fig. 6). With that effort, these documents will be preserved for many years to come. Over the past several years and in collaboration with the NPS, we have expanded this effort by digitizing some of the most important of these documents. Digital copies of these documents will be stored in an NPS database, making them widely available to anyone interested to see or study them.

The digitization phase of curation is completed and the curation of bone specimens is ongoing, a project funded in part by the NPS. Both aspects have benefited greatly from the contributions of Liz Valencia (NPS) and Brian Hoduski (NPS). Other key contributors to these efforts include Martin Hobmeier (NPS), Greg MacDonald (formerly with the NPS), Grace Parikh (MTU), Zachary Merrill (MTU), John Henderson (MTU), Noah Yacks (MTU), Michael Paul Nelson (Oregon State University), Lindsay Hiltunen and staff at the MTU Archives, and Leah Vucetich (MTU). Because the collection is large-the largest in the world-continuing the effort to update the curation of bone specimens is ongoing.

\section{THE IMPORTANCE OF HEALTHY TEETH}

Wolves, moose, humans-we're all mammals. What makes a mammal special is live birth and mother's milk. Well that's pretty important, but what really set us apart from other animals are our teeth. Think of it. Birds don't have any. Our cold-blooded brethren who swim or slither-they have the crudest little spikes. But mammals have the most glorious teeth, perfectly suited to their lives. Wolves have little nibblers front, finely forged daggers just behind, and bone-crushing grinders toward the back.

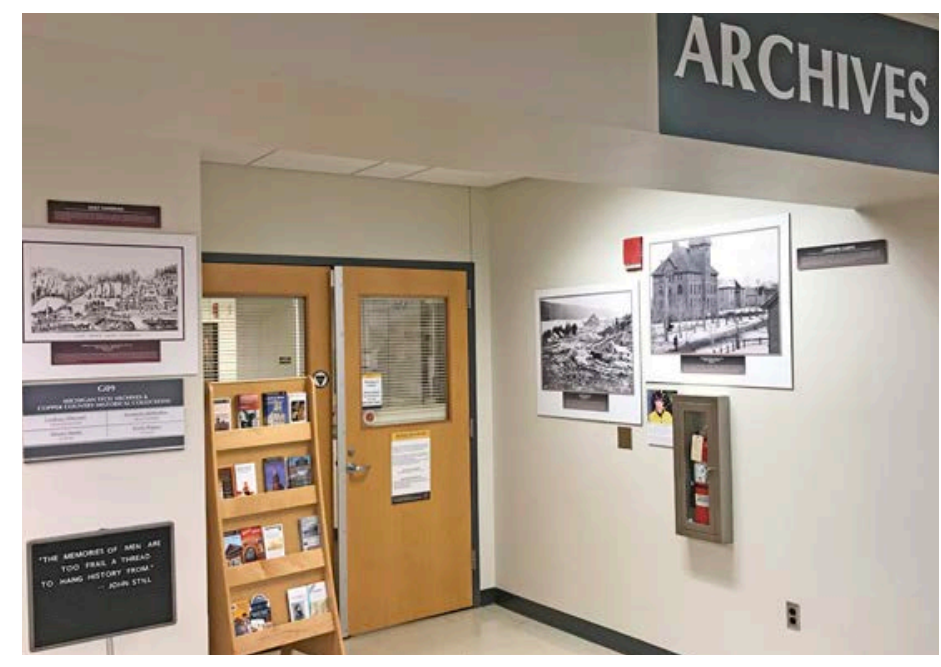

Fig. 6 Original records and data from long-term research on wolves and moose at Isle Royale are catalogued and maintained at the Michigan Technological University Archives and Historical Collections.

Moose have different lives and they show it in their teeth. The leaves and twigs they eat are easy to find and capture, but impressively difficult to digest. Digestion is executed in phases, the first of which is mechanical crushing and grinding that takes eight hours of every moose's day. Another phase-cud chewing-is almost the same and just as time consuming. The better crushed and ground, the more surface area on those small bits of vegetation, and surface area is where all the biochemical digestive processes occur in the four-chambered stomach and gut. All this pestling and comminuting requires teeth built as tough as a Ford F-350.

The long mouth of a moose is lined with six pairs of broad molars and premolars on the left and another six pairs on the right. These teeth are also sharply ridged (at least at birth, before they are worn down by a lifetime of chewing), and moose have a specially adapted jaw joint that is loose enough to allow those ridged teeth to grate past each other side-to-side for some serious mastication.

Healthy teeth clearly contribute mightily to the well-being of any mammal. A few years ago, we met a dentist who was visiting our summer research station on Isle Royale. She took great interest in the collection of jawbones and skulls we'd collected to that point in the season-especially in the teeth. She set our eyes on a tiny detail for which we are very grateful. She pointed out how it was pretty easy to find little holes on the top (occlusal) surface of the molars and premolars in the dozen or so specimens that she examined. The holes were just about a millimeter (one twenty-fifth of an inch) in diameter, what dentists refer to as dental caries, or tooth decay, or simply cavities (Fig. 7). 


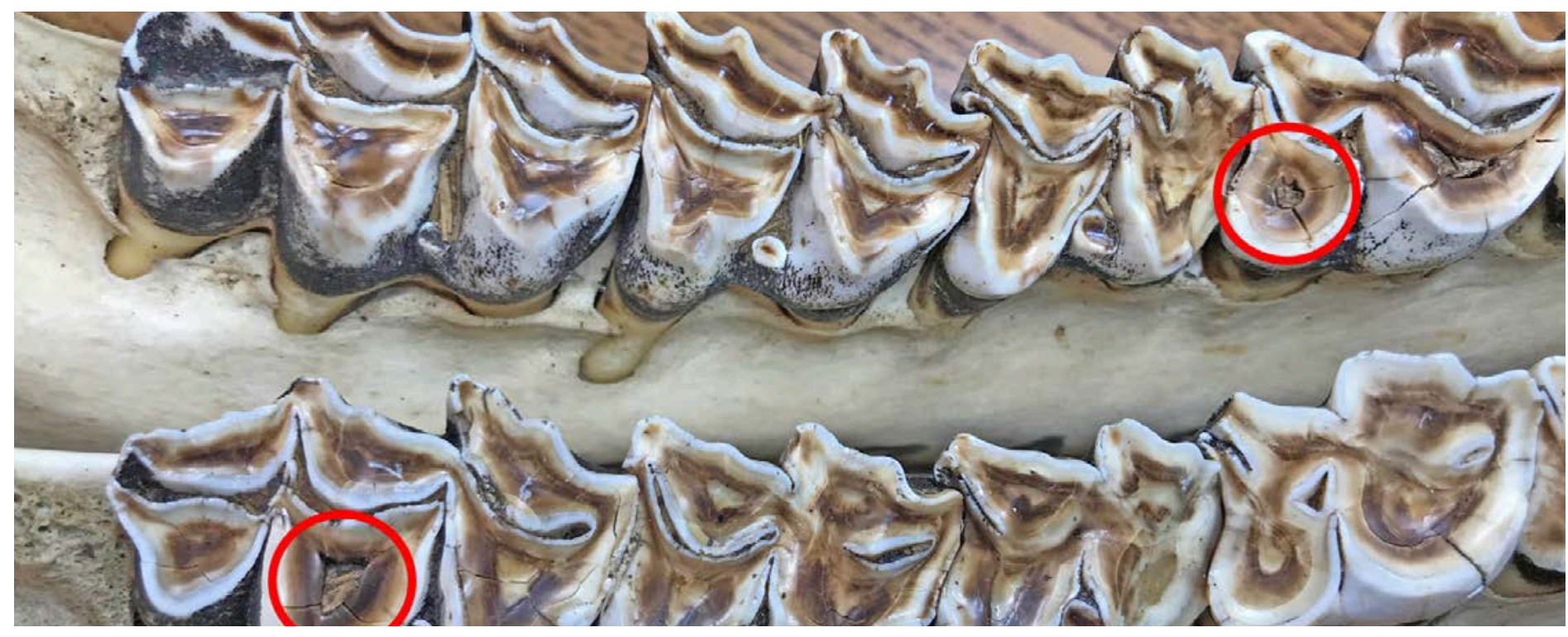

Fig. 7 Dental caries (cavities) in moose, associated with advanced age, may lead to debilitating bone infections. When bone infections occur in the mouth they give off an odor that is likely detectable by hunting wolves. Two examples of dental caries are circled. Perhaps you can see a third.

We took interested mental notes, but didn't act on the dentist's excitement. At about the same time, Allie Johnson began working with the wolf-moose project as an undergraduate student at MTU. While Johnson was mainly occupied with moose bone curation, described earlier, her interest deepened over time, and she wanted a richer experience. She is the right person to begin a systematic study of dental caries in moose teeth. We are starting at the very beginning, because virtually nothing is known about the epidemiology of dental caries in moose.

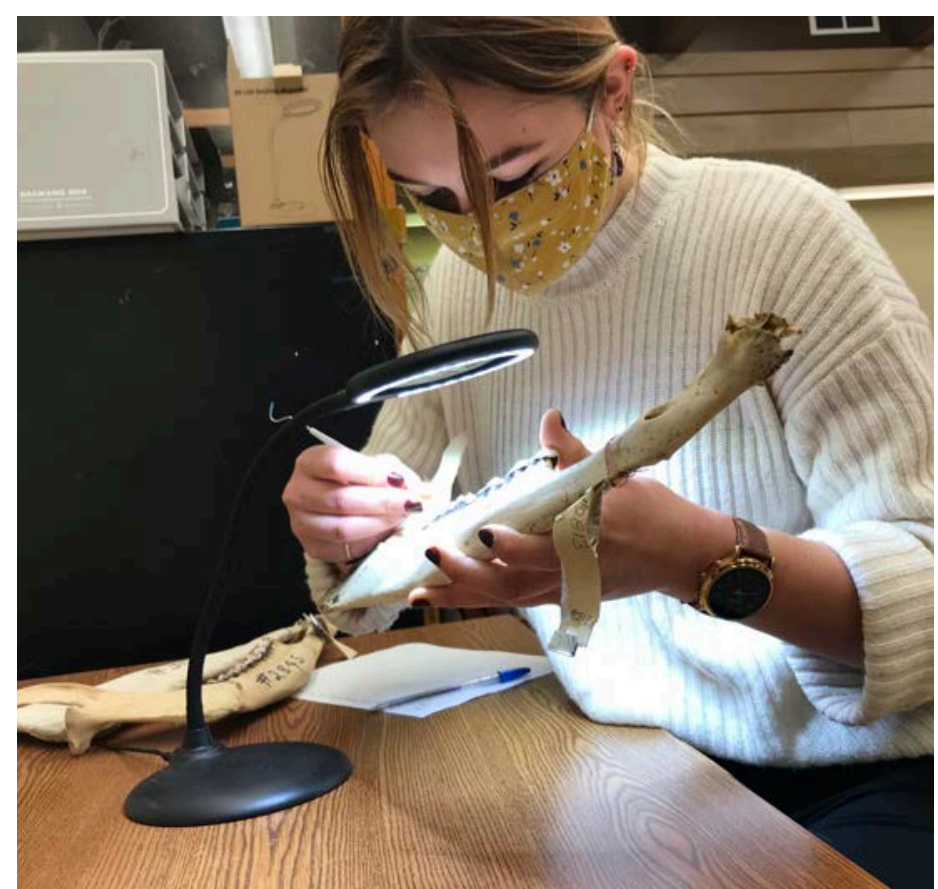

Fig. 8 Student researcher Allie Johnson is conducting a study of dental caries (cavities) based on mandibles collected over a 60-year period.
After getting the hang of spotting these little holes with the aid of a lighted magnifying glass and dental pick, the research methodology is as easy as 1-2-3. Literally, the method is to count all the holes in the teeth of each jawbone. Counting (sometimes up to 12 ) is not the limiting factor. The limiting factor is the patience to carefully inspect many hundreds of teeth (Fig. 8).

We are still in the earliest stages of this research, but Johnson has already shown us quite a bit. Dental caries appear more common in males than females. Maybe their diets are different? Perhaps the teeth that males grow are less durable than the teeth of females? At this early stage, we're not sure.

The frequency of dental caries increases with the age of the moose. That is not surprising, but it is important to have documented. This finding means that the dental caries of a moose belong to a large class of diseases known as senescent (or age-related) pathologies. The relevance of that classification shows itself in a moment.

In the upcoming months, we plan to assess whether there is any association between the number of dental caries of a moose and the length of their metatarsus, which is the longest bone in the foot of a moose (human as well). Moose walk on their tiptoes (hooves), so the metatarsal bone of a moose looks to most humans like the lower part of their rear leg (Fig. 9). The moose metatarsi are typically 360-400 millimeters (14-16 inches) long.

Now you might be wondering, what interest might there be in assessing the possible connection between den- 
tal caries and the length of a foot bone? First, metatarsi and teeth both develop when moose are young, before a moose is 12-18 months of age. Second, metatarsal length is an indicator of nutritional stress early in life. Moose with a stressful start to life tend to have smaller metatarsi. If small moose that had a stressful start to life also developed poor-quality teeth, then they may be more prone to developing dental caries.

A third connection between teeth and metatarsi reveals itself by appreciating that developing organisms have only so much energy to devote to the development of their bodies. Limited energy means that investment in the development of one area prevents investing that energy in the development of another area. Investment in high-quality teeth is an investment for long life-because living long requires teeth that are built tough enough for a lifetime of pulverizing plants. But investing in a long life vis-à-vis high-quality teeth may have to be traded for reproductive prowess. For bulls, in particular, reproductive success tends to increase with body size because being large is how bulls demonstrate their worthiness as a mate. So, our interest in teeth and feet is also to see if they represent a means by which moose trade investments in longevity for investments in increased body size.

We'll keep you posted as this research develops. For now, we are confident of one practical lesson of the research. That would be, please don't forget to brush and floss.

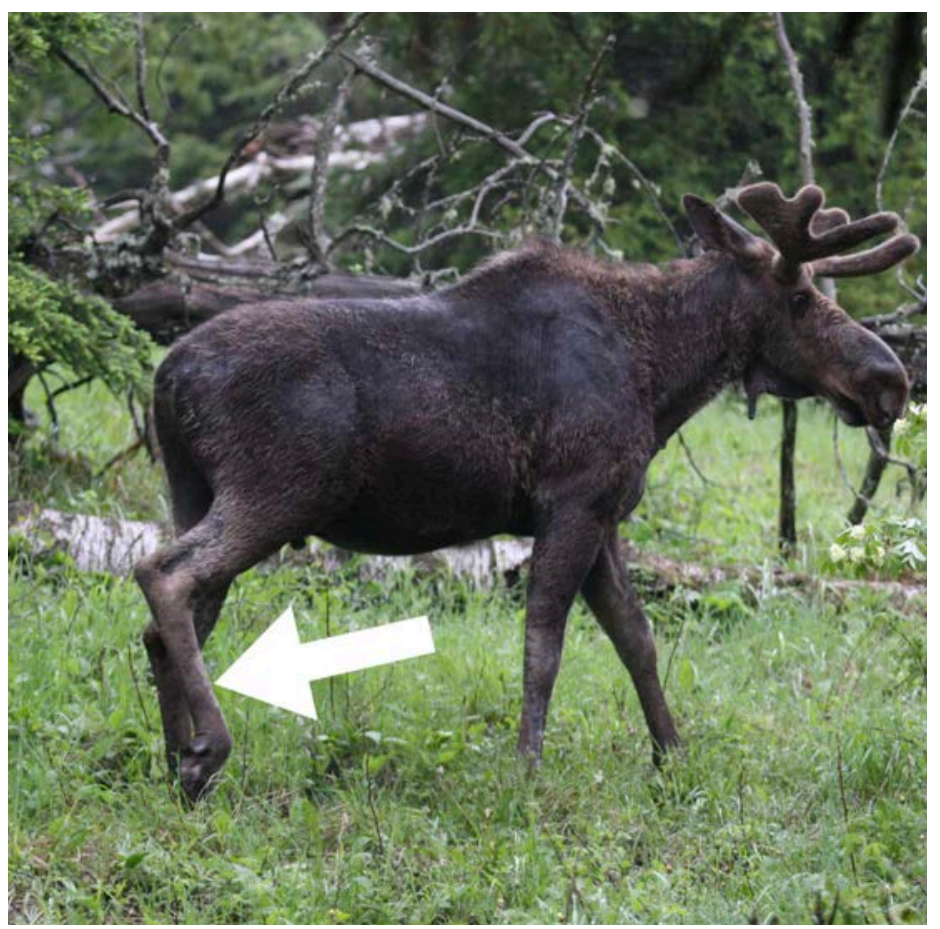

Fig. 9 The length of metatarsal bones-lowest long bone in the rear leg of moose (arrow)-provides an indicator of nutritional health experienced as a fetus and young calf.

\section{THE UPS AND DOWNS OF MOOSE NUTRITION}

Animal populations are dynamic, forever fluctuating in abundance, and ecologists have long endeavored to better understand what sustains this dynamism. Ecologists frame their approach to this understanding by classifying any imaginable influence on a population as either biotic or abiotic-that is, biological influences on one hand and nonbiological influences on the other. Biological influences include processes like predation, competition, and the availability of food. Nonbiological influences include things like physical habitat, the availability of water, and weather, such as fluctuations from year to year in the severity of winter. That framing sets up a rather simple-sounding question: To what degree are fluctuations in the abundance of moose driven by wolf predation, competition among moose for food, and weather?

We can enrich that question by taking note of a simple fact: Populations are comprised of individual animals, and population dynamics rise from the aggregated experience of all those individuals. This brings us to nutrition. If most of the moose in a population are in good nutritional condition, then they are more likely to survive the year and successfully reproduce. As such, the nutritional condition of individual animals is thought to be key to understanding population dynamics.

We've hitched those twin ideas about nutrition and the biotic-abiotic taxonomy of influences affecting population dynamics to data from the wolves and moose of Isle Royale. Doing so has brought us to some interesting answers and even some new questions.

Before getting to the answers and new questions, let us tell you what we did in the field. Every winter we find and follow the tracks of moose. When we find urine-soaked yellow snow, we collect a sample. The moose urine in this yellow snow contains urea and creatinine, two chemicals that can be used to tell us whether and to what extent a moose was starving. We've collected more than 2,000 yellow snowballs over the past 30 years.

From that information we could see that the average ratio of urea to creatinine in the urine of samples differed greatly from one winter to the next (Fig. 10). During some winters most of the moose seem to have been doing very well nutritionally. Other winters were, we can only say, grim, with many apparently starving moose. For example, in a good year less than 5 percent of the moose are starving and have substantially reduced condition, whereas in a bad year almost 25 percent of moose are starving. *

*Those values are the 20th and 80th percentiles for the sample of years for which we have data, 1988-2017. 


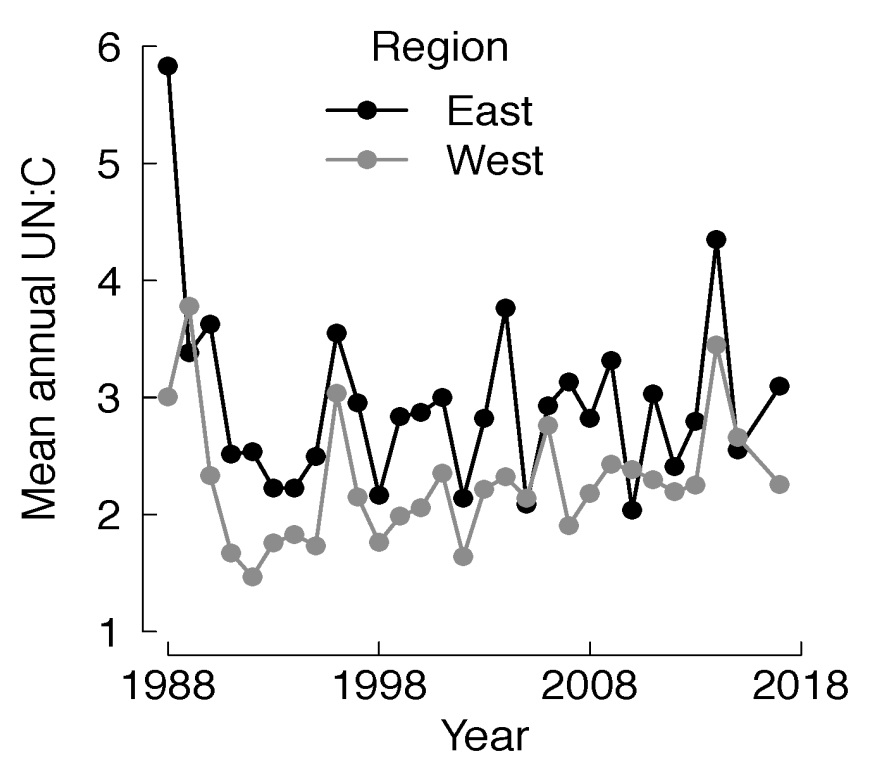

Fig. 10 Temporal trends in UN:C for the Isle Royale moose population. UN:C is the ratio of urea nitrogen to creatinine (UN:C) in urine-soaked snow. The snow was collected by following the tracks of moose in the snow during the winter. $U N: C$ is an indicator of nutritional stress with larger values representing greater nutritional stress. One of our research goals has been to understand what causes these fluctuations, as well as the consequences of these fluctuations for the population dynamics of Isle Royale moose.

That variation in nutritional condition got us to wondering: Why? What factors are most important in driving those fluctuations from year to year? We had a few ideas.

- Maybe poorer nutritional condition occurs when moose compete more intensely for limited food. If so, one might expect years of poorer nutrition to be associated with years with more moose.

- Or, maybe poorer nutritional condition is an indirect consequence of being exposed to too much predation risk. In other words, in years when a moose has a higher chance of being killed by a wolf, moose might be more likely to forage in habitats that are safer from wolves, but perhaps also have lower-quality food (Fig. 11). Prior research had given us reason to think this might occur [6]. If so, then nutrition might be poorer during winters with greater predation risk.

- Finally, poorer nutrition during the winter might result from snowier winters and preceding summers that had been hotter. When the snow is deep it can restrict moose's ability to move from one good foraging patch to the next. And moose are easily heat-stressed during summer, so moose respond by spending more time resting in the shade or in lakes and, consequently, spend less time foraging. The end result is that moose might enter winter in generally worse condition after a hot summer.
The next step is all math-y and brimming with numbers. We ordered our data into neat columns and presented it to statistical algorithms capable of telling us the extent to which each of the ideas is supported by the data.

Before telling you what we found, we should say what we expected to find. We pretty much expected to find what ecologists usually find: that each of the three ideas would contain a little truth, and we'd strain and squint to discern whether one factor was more important than another.

But that's not how it turned out. What we found is that climatic factors explained $66 \%$ of all the year-to-year fluctuations in nutritional condition, with nutritional condition being worst for moose during winters with deep snow and during winters that followed warm summers (Fig. 12). This result is consistent with concerns that climate change is likely to affect moose and similar species around the world.

What about the biological factors-moose abundance and predation risk? They explained virtually none of the fluctuations in nutritional condition. Predation is important in many ways, but any behavioral responses of moose to wolves does not seem to have a strong impact on the average nutritional condition of moose during winter.

Right now, these research results are being reviewed at a top-ranked scientific journal, and we expect the results to be published later this year. The coauthors of this research are Sarah Hoy, John Vucetich, Daniel Melody, Leah Vucetich, Rolf Peterson, Ky Koitzsch, Lisa Osborn Koitzsch, Andrew Von Duyke, John Henderson, Grace Parikh, and Jennifer Sorensen Forbey (of Boise State University).

One of our next research ambitions is to assess the extent to which nutritional condition explains fluctuations in moose abundance. That relationship is presumed to exist, but few are able to assess the relationship over so long a period of time.

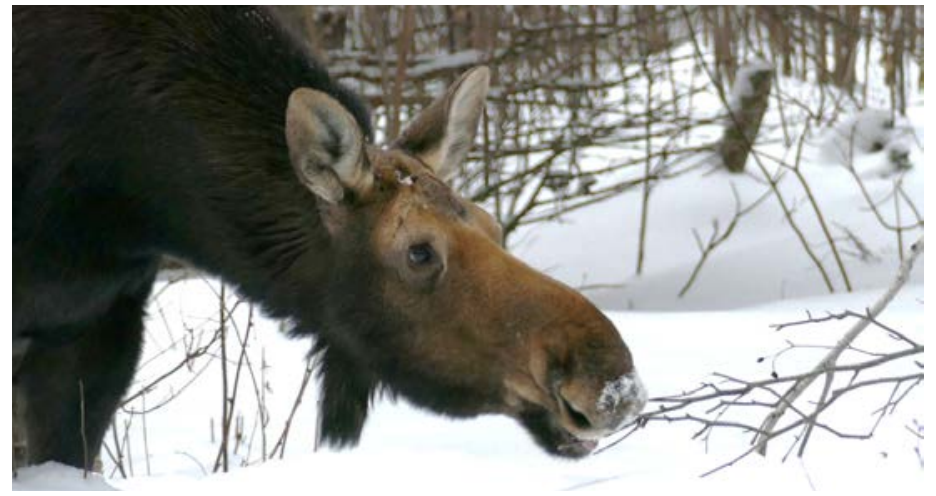

Fig. 11 Moose foraging in winter find a meager supply of browse at Isle Royale, and they metabolize internal stores of fat to survive until green leaves appear in spring. 


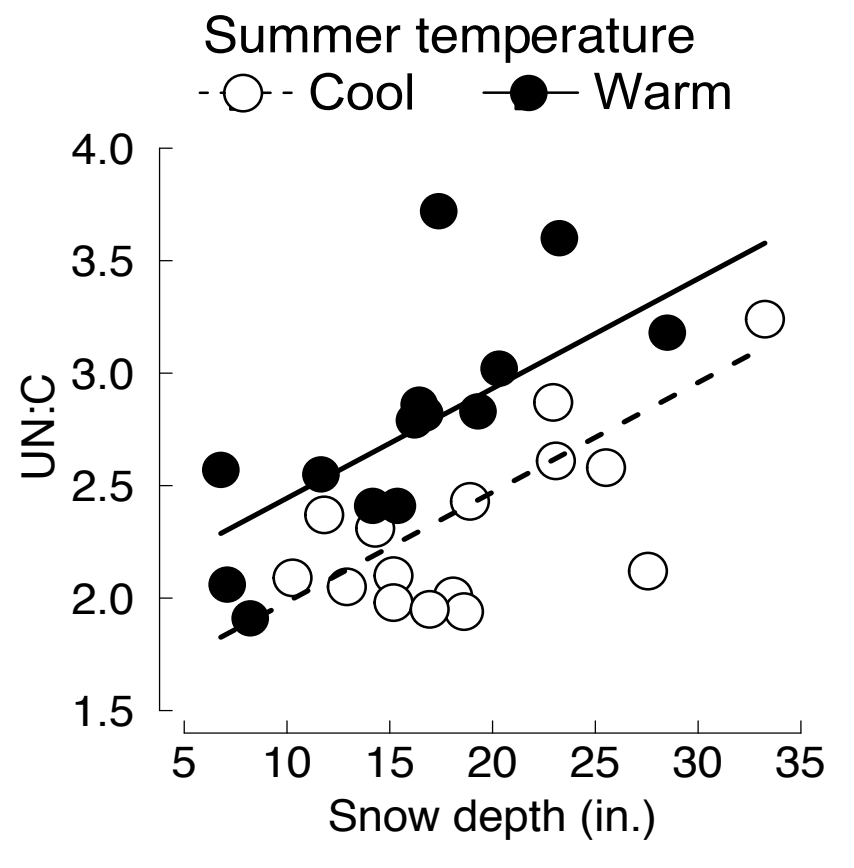

b)

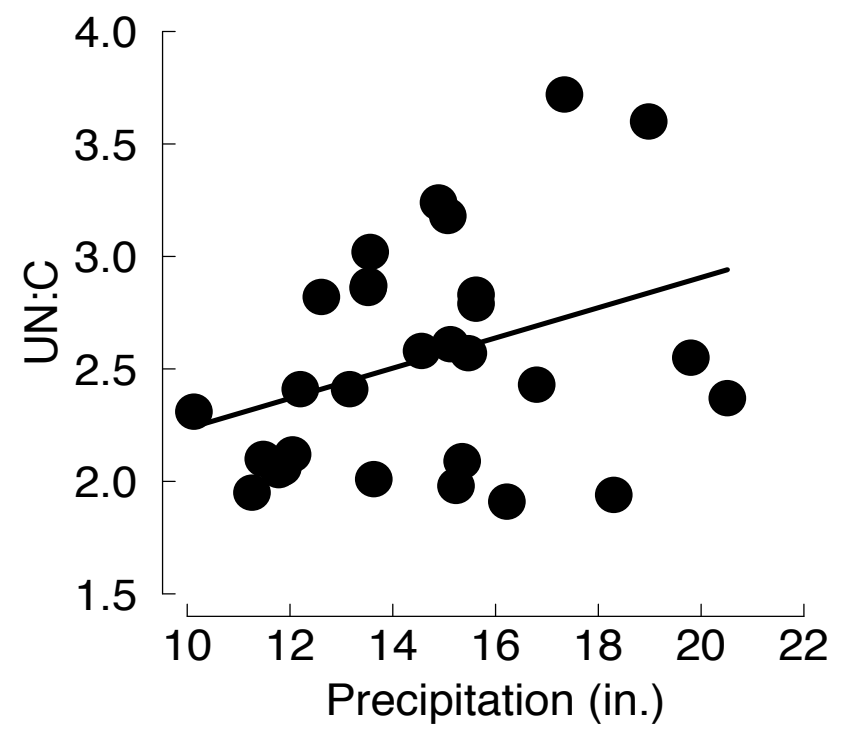

Fig. 12 UN:C (an indicator of nutritional stress) shown in relation to snow depth (upper panel) and precipitation during the previous summer (lower panel). Average temperature during the previous summer also influenced nutritional stress, with warmer summers being more stressful. Larger values of UN:C represent greater nutritional stress (see Fig. 10 for more details). Each symbol represents a different year between 1988 and 2017.

Oh, there's one more important detail. I'd mentioned that "we" had collected all those yellow snowballs. Well that deserves a little qualification. For most of the past 10 years, those snowballs have been collected almost entirely by Lisa and Ky Koitzsch (Fig. 13). We'd never be able to share this story were it not for all their long, exhausting days in the field tracking moose each winter.

\section{WOLVES PREFER TO EAT CALVES, EVEN WHEN THEY ARE HARD TO FIND}

Earlier in our report, we mentioned that the number of animals in a population is forever fluctuating up and down. Animal populations are dynamic in a second way-far less obvious, but no less important. This second dimension of eternal flux emerges from an unpretentious observation: Animals age. Humans, for example, are usefully described as young, middle-aged, and old. Moose are no different, but we use the words, "calves, prime-aged, and senescent." ${ }^{\dagger}$

Age shapes not only the experience of an individual moose, but also the essential character of an entire population. For instance, when populations are mostly comprised of moose in their prime, the population tends to grow rapidly. By contrast, when populations are mostly comprised of senescent adults, they are more likely to decline, as senescent adults have lower rates of reproduction and survival. Ecologists say that the "age structure of a population fluctuates," and these fluctuations can be significant. In some years, as much as 52 percent of adult moose on Isle Royale were senescent. In other years, it's been as low as 6 percent. Age structure is the second basic dimension of dynamism in a population, and it has big implications for wolf predation.

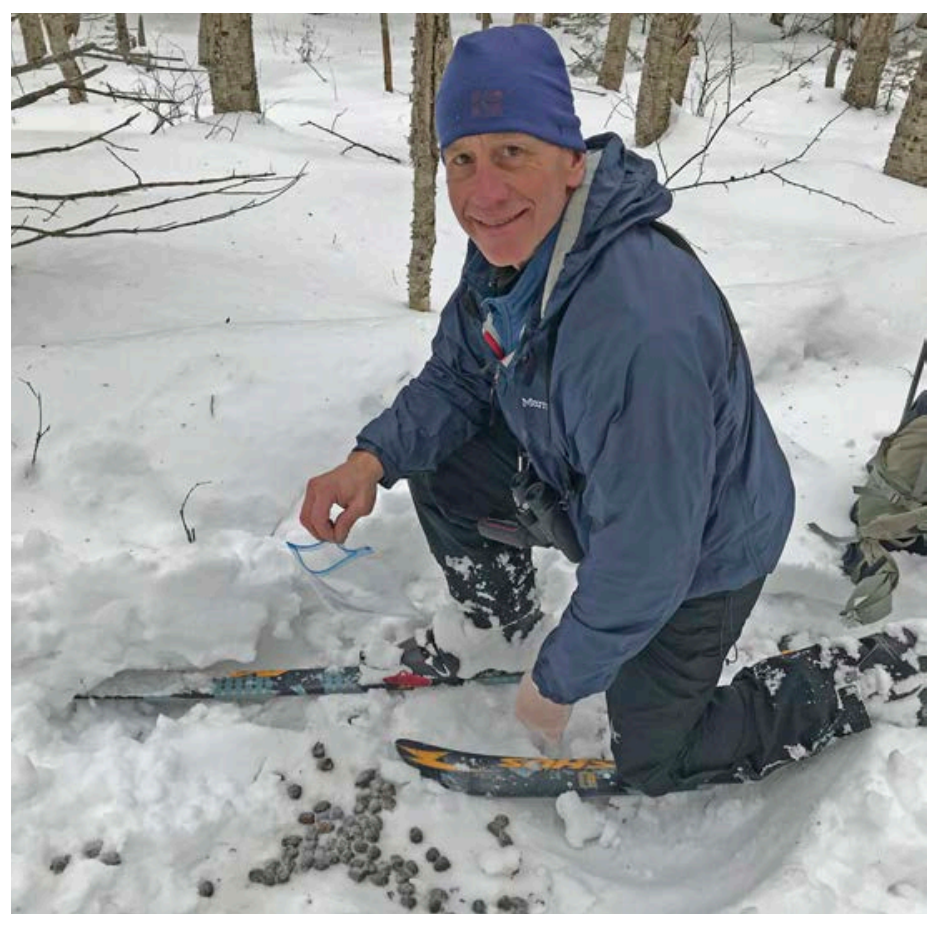

Fig. 13 Ky Koitzsch prepares to collect a sample of moose pellets in winter with a gloved hand. Photo by Lisa Koitzsch, the other half of a field team that has provided a key effort for the past decade.

\footnotetext{
† Calves are less than 12 months old. Moose live their prime years until about nine years of age. Senescent moose make it to their late teens.
} 


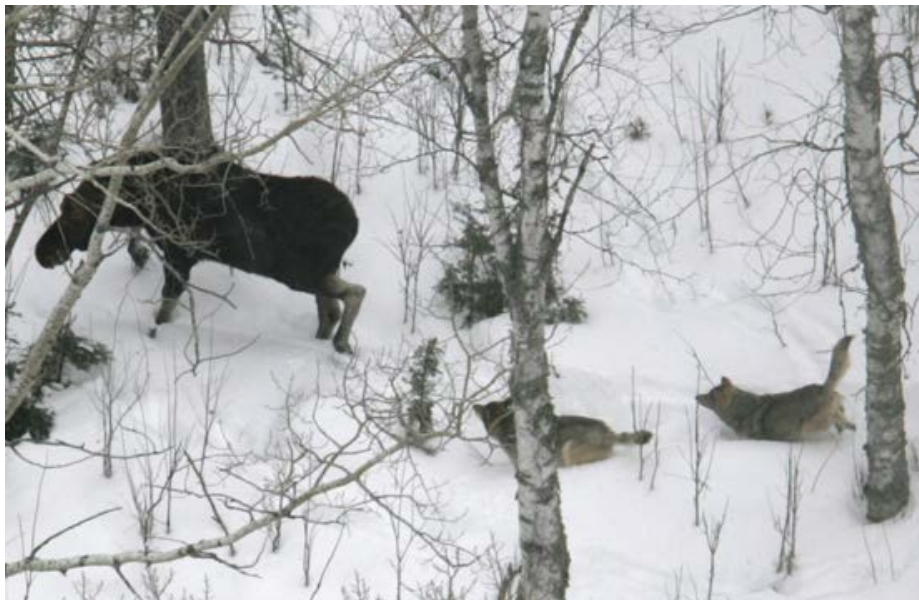

Fig. 14 Wolves close in on an adult moose in winter, but to no avail, as the moose was able to adequately defend itself.

To see how, consider another simple observation: An adult moose is about 10 times the size of a wolf. So, it's no surprise that when given the choice, wolves tend to kill calves and senescent moose and tend to avoid prime-age moose (Fig. 14). Ecologists have known this since the 1960s when the pattern was first observed on Isle Royale. The unanswered question-well, unanswered until just this year-had been, does that pattern of age-based preferences change in any important way as the moose population's age structure fluctuates? Or, to put it more plainly, what do wolves eat in years when their preferred prey, calves and senescent adults, are relatively rare compared to prime-aged moose? Either way, the question is certainly laced with erudite nuance, but we will also see how it fledges an answer with much broader appeal.

To answer the question, one needs to know how many moose were alive each year and how many moose were killed each year by wolves. There's more. One also needs estimates for the age structure of the moose population each year and ages of the moose killed by wolves each year. And, one can't answer the question with a year or two of such data, or even eight or 10 years of data. A good answer requires decades of that kind of data. While the required data is rarer than a royal flush, we are fortunate to have five decades of it.

With that data, one can compare age structure of the living moose to that of moose killed by wolves for each year. The difference between what's available to wolves and what wolves eat provides a measure of how strongly wolves prefer a certain type of prey. The difference is summarized in a precise and formal way with the Manly-Chesson Selection Index $(a)$, an alphabet soup whose recipe is $a_{i}=\left(r_{i} / e_{i}\right) /\left(\left(r_{i}\right.\right.$ $\left.\left(e_{i}\right)+\left(r_{j} / e_{j}\right)\right)$. We stirred our data into that soup, and from the steam emerged a pattern: Wolves' preference for calves was strongest when calves were relatively rare (compared to other ages of moose) and weakest when they were relatively common (Fig. 15). In other words, we found wolves still showed strong preference for calves, even in years when calves were relatively rare and wolves showed no signs of starting to switch and prey on the more abundant, but difficult to catch, prime-aged moose. We observed a similar pattern for senescent moose, though not quite as strong. Scientists are never satisfied with plain-language descriptions. So, you won't be surprised to know that there is a members-only way of referring to this pattern. They call it "negative, frequency-dependent selection." Goodness gracious!

Awkwardly named or not, that pattern represents a death-defying trade-off. Wolves are routinely on the verge of starvation and usually benefit from at least just a little more food. But negative, frequency-dependent selection is no way for wolves to maximize the rate at which they capture food. Negative, frequency-dependent selection causes wolves to spend more time looking for their preferred prey type (calves) when that prey type is rare. But getting enough food is about as important as not being

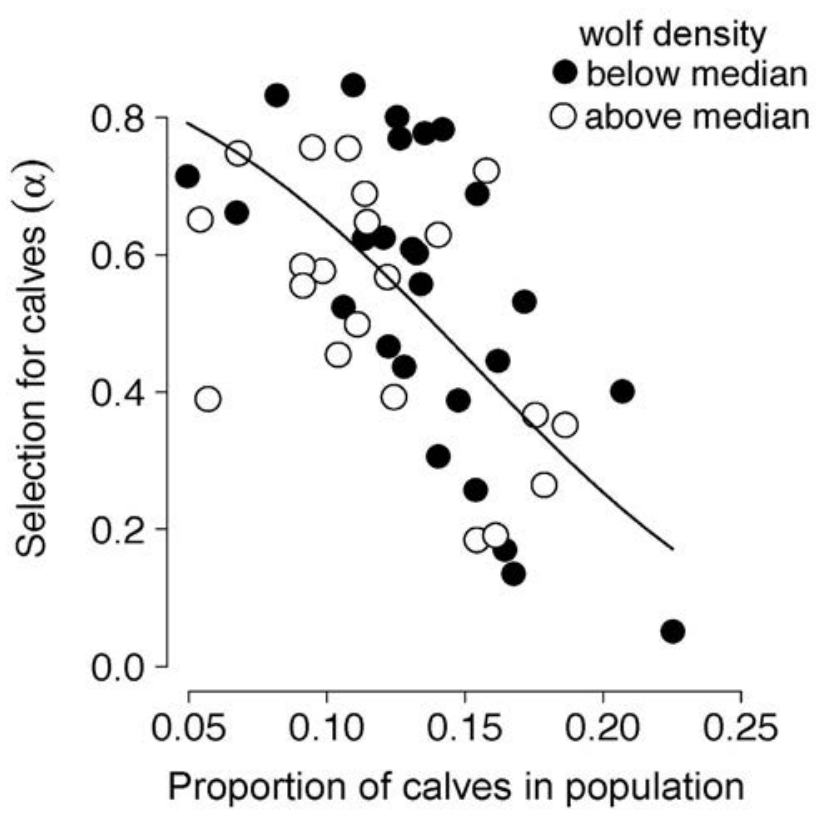

Fig. 15 The relative frequency of calves in the moose population in relationship to the Manly-Chesson Selection Index, which indicated the strength of preference that wolves have for selecting calves. Each symbol represents a different year between 1959 and 2007. Notice that calves represent as little as about 5 percent of the moose population up to as much as about 20 percent of the population, depending on the year. Also, note that minimum and maximum possible values of the selection index are zero and one. Wolf density also had a minor influence on the strength of selection, as indicated by the different kinds of symbols. 
killed by your food, and moose are the kind of food that can kill or seriously injure a wolf. The risk of getting clocked in the head by a 900 -pound moose or hurled against a very solid tree trunk is ever-present. Prime-aged moose are the riskiest moose to kill because they are bigger and savvier than calves, and tend to be in better health than old, senescent moose. Wolves' tendency to vary their preference for calves and senescent moose (in that negative, frequency-dependent manner) is very likely the result of accepting the extra time it takes to find vulnerable prey as a way of reducing the risk of being killed by what they hope to eat.

Do you recall the advice of your elementary school teacher about using new vocabulary in a sentence three times a day? Well, we've done it-used "negative, frequency-dependent selection" three times. Of course, we'll understand if you're unable to work that phrase into any of your conversations today-except perhaps when you share these interesting ideas with your friends and family.

Managing the trade-off between getting enough food and avoiding injury is a wolf's day-to-day experience of life. But, that trade-off also has big implications for fluctuations in the abundance of animal populations. Understanding how requires a detour in thought.

About a hundred years ago the mathematician Vito Volterra developed a pair of equations that describe the dynamics of two interacting populations, a predator and its prey. Those equations have shaped scientific beliefs about how nature works to this very day. In particular, the most basic elements of predator-prey dynamics are what mathematicians call "neutrally stable." In other words, predator-prey dynamics seem to be on a knife's edge. Modify the math in a tiny way to represent some real-world feature of ecology, such as the inclusion of a carrying capacity (which accounts for competition among prey for their forage), and fluctuations in abundance are greatly dampened. Modify the math in some other tiny way, say, by increasing the numerical value assigned to the carrying capacity, and fluctuations in abundance are greatly accentuated, sometimes to the point of extinction.

In real life, populations of predator and prey run the gamut from pretty stable to not so very stable. This state of natural affairs has set lifelong purposes for some of the best ecologists over the past century. Namely, to contribute to a slowly growing catalogue of animal behaviors, each classified according to its effect on populations-to dampen fluctuations, accentuate fluctuations, or have no significant effect on fluctuations. We wanted to investigate whether negative, frequency-dependent selection-the behavior we'd seen in Isle Royale wolves-affected how stable and resilient the predator and prey populations were.

The assessment, in a nutshell, involves building two mathematical models-not unlike the models that Volterra builtwith each model representing the wolves and moose of Isle Royale. The first model included math to account for the dynamic patterns of preference that we'd seen in Isle Royale wolves. The second model was identical, except that it ignored the dynamic behavior and supposed that the strength of selection for calves and senescent moose was constant over time.

The comparison of those models showed that negative, frequency-dependent selection (the predatory behavior we observed on Isle Royale) leads to the accentuation of fluctuations in abundance of wolves and moose. We know that the wolf and moose populations on Isle Royale are pretty dynamic, and now we can count this behavior among the processes that favor that dynamism.

This research will be published in the journal Animal Behaviour and includes a similar analysis of wolves who prey on elk in Yellowstone National Park. The coauthors of this research are Sarah Hoy, John Vucetich, Rolf Peterson, Daniel MacNulty (Utah State University), Matthew Metz (NPS), Daniel Stahler (NPS), and Douglas Smith (NPS). We're all proud to have contributed to this century-old effort to deepen the understanding of animal populations.

\section{A RIPPLE EFFECT OF WOLVES ON THE WATER}

"Trophic cascade" is scientific jargon that describes an ecological chain reaction, where changes in the abundance of a predator (like wolves) leads to a change in abundance of prey (like moose), which leads to changes in the community of plants upon which prey forage. The first trophic cascades were described in the late 1970s and early 1980s in lakes and marine systems. The most widely known of these trophic cascades involves otter who eat sea urchins, which eat kelp. The first-ever trophic cascade to be detected on land was discovered in the mid-1990s with the wolves, moose, and forest of Isle Royale.

An enduring question about trophic cascades has pertained to better knowing how intensive and extensive they are. For example, in Yellowstone, wolf-triggered trophic cascades are extremely intense where aspen and willow grow, but aspen and willow occupy a relatively small portion of the Yellowstone landscape. Grasslands are much more extensive in Yellowstone, but trophic cascades have been difficult to evaluate in those habitats. And, trophic cascades may not occur to any appreciable degree in large tracts of higher-altitude habitats dominated by lodgepole pine, which elk do not eat. 
Isle Royale affords more opportunity to answer questions about the intensity and extensiveness of trophic cascades. While we have long known of wolves' intense indirect effect on the forest, we are just beginning to develop a deeper understanding of how wolf-triggered trophic cascades might affect aquatic ecosystems.

Let's start toward the bottom of an aquatic food chain with watershield (Brasenia schreberi), which is the kind of native aquatic plant that can really dominant a small, shallow lake or pond. It holds fast to the bottom with a tuberous root, up from which rises a skinny little stem topped with a floating leaf. Watershield can outcompete other plants by both shading and biochemical warfare-secreting a slimy biochemical film that interferes with many bacteria, algae, and other plants.
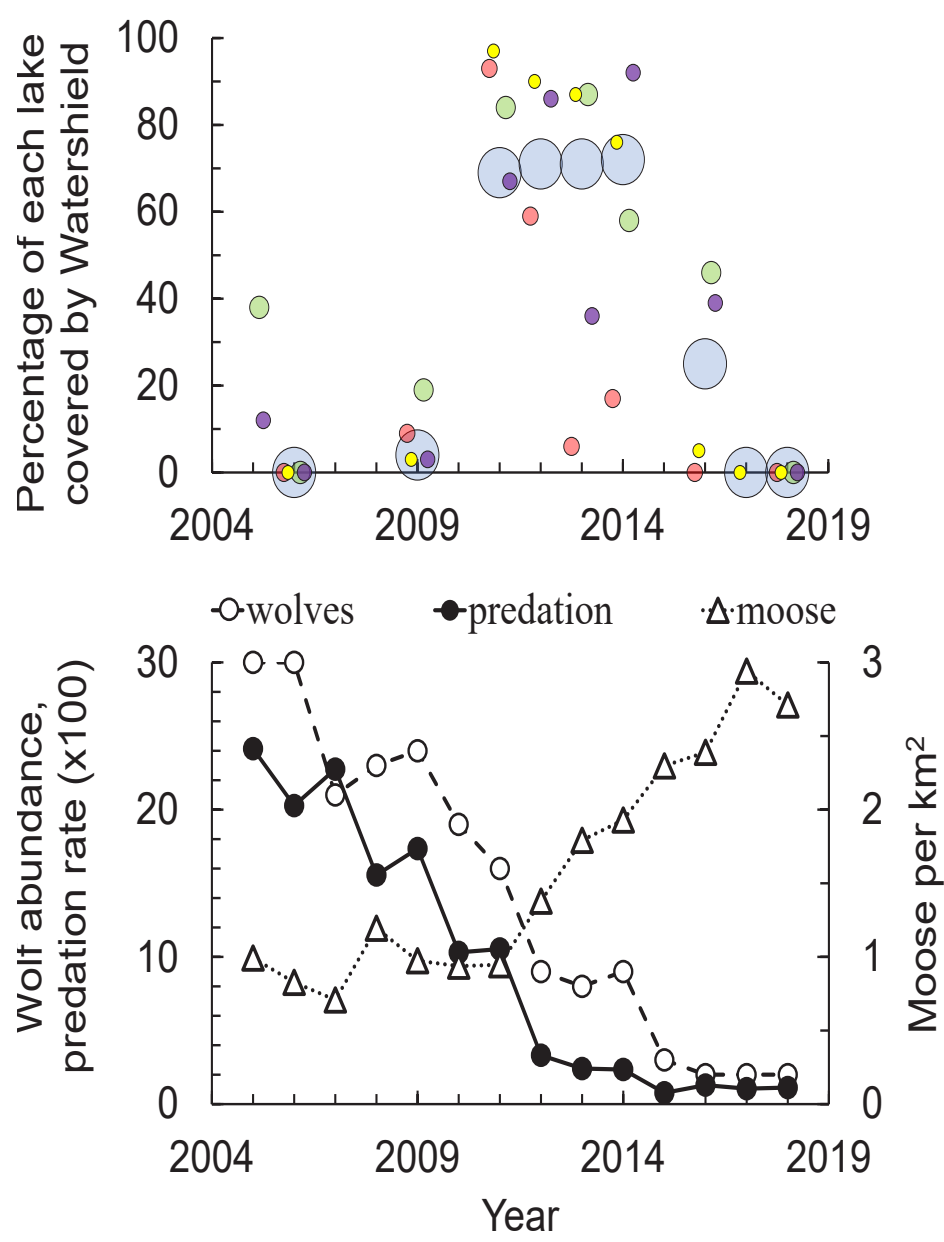

Fig. 16 Temporal trends in the proportion of five lakes' surface covered with watershield, 2005-2018 (upper panel). The five lakes are Lake Ojibway (blue), Moose Creek Lake (green), Y-shaped Lake (red), Moose Lake (purple), and Daisy Farm Lake (gold). The size of the circles corresponds to the size of the lakes. The lower panel shows temporal trends in moose density, wolf abundance, and predation rate for 2001-2018.
While watershield is capable of such domination, it does not always dominate. But it did for a time in the 2010s on several of Isle Royale's lakes and ponds. Our attention was drawn to the changes by our good colleagues, Brenda Bergman and Joseph Bump (University of Minnesota), then at MTU, who were studying aquatic herbivory by moose and beaver at the time. Part of their research was to build large circular aluminum "cages" in the shallows that protected aquatic vegetation from moose herbivory and beaver herbivory [7]. These exclosures were also designed to explore which species (moose or beaver) had a greater impact on vegetation. One result of those exclosure experiments is, we have learned that moose eat quite a lot of watershield (and other aquatic plants) when it's available, more so than beavers.

After Bergman and Bump finished their studies, we kept an eye open to subsequent changes in watershield. We augmented shoreline observations with satellite and aerial photography (when watershield really dominates it can be seen in a satellite image). The imagery allowed us to take a look back in time before we'd paid such close attention.

We discovered that watershield was very abundant on five ponds and lakes from 2011 to about 2015, but not before or after. The dramatic rise and subsequent fall of watershield coincided with a period of wild flux for the moose population (Fig. 16). Moose abundance had been driven to very low levels by 2004 and remained low for several years afterward. That decline was driven by rates of predation that remained high until about 2009. After moose had been low for several years running, watershield then rose to prominence.

As watershield grew to dominate those ponds, inbreeding took its toll on the wolf population, wolf predation declined, and moose abundance increased more than fourfold. Aquatic browsing by moose intensified. They ate not only the plant greens, but also ate roots in the early spring before the greens even started to grow. Over about a three-year period the abundance of watershield returned to very low levels, where it has remained since.

The abundance of watershield is influenced by many biotic and abiotic influences. Among those influences, moose herbivory would seem to be particularly powerful-at least in some ponds and lakes. Of the four dozen lakes and ponds on Isle Royale that are large enough to be named, five lakes and ponds exhibited that chain reaction beginning with wolves and ending with watershield.

An important, albeit incomplete, explanation for why watershield can dominant some aquatic ecosystems, but not 
others, is that watershield is more or less limited to water less than six feet deep. So, watershield is less likely to ever dominate a deep lake. In the end, we've gained a smidge more insight on that question about how intensive and extensive wolf-triggered trophic cascades can be. They can be very intense, and they are extensive enough to reach aquatic ecosystems. It's incredible to think that a predator which barely sets foot in lakes and ponds appears able to elicit changes to aquatic ecosystems that can be detected in photographs taken in the outermost layer of the earth's atmosphere. More work is required to better understand the extent to which other lakes are indirectly affected by wolves in ways that do not necessarily involve watershield.

When wolves send a ripple that reaches watershield, the changes do not stop there. Watershield, itself, can be a big player in an aquatic ecosystem. When watershield is abundant, it outcompetes other plants and can depress the water's oxygen content, which impacts zooplankton, upon which many fish feed. Watershield can also be a source of food for vertebrates including ducks and beavers.

This brings us to the beavers on Lake Ojibway, which was created in the 1950s when beavers sealed off a low-lying wet meadow with two beaver dams, one at each end of the pond. The water level and size of the pond increased, and Lake Ojibway became a well-defined lake. During the 1960s, moose density was relatively low (about one moose per square kilometer), and photos from that time show that watershield was abundant.

When aquatic plants are especially abundant, beavers feed year-round on the succulent green leaves. The benefit of such a diet is to greatly reduce the time beavers spend foraging on land, where they might encounter a hungry wolf. The beavers who made Lake Ojibway their home in the early 2000s seem to have had this luxurious abundance of aquatic plants. In 2006, the lake was occupied by four active beaver lodges, a large number for a lake that size, and among the largest beaver lodges on Isle Royale. While the lake was teeming with beavers, it was conspicuous that we were unable to observe even a single tree to have been cut by beavers on the land surrounding the lake, despite having looked carefully. Apparently, aquatic plants provided all the food they wanted, and beavers built their dams with rocks, mud, and dead wood.
But conditions changed over time, and not in a good way for these beavers. A decade later (in October 2017) beavers were observed to have been cutting aspen trees on the land surrounding Lake Ojibway for the first time in years. Those cuttings were an important clue that aquatic forage had been importantly depleted.

Then catastrophe struck. In November 2017, the primary beaver dam impounding Lake Ojibway failed. Half the lake drained, and the four beaver lodges were left high and dry. At the time, there were only two wolves remaining on Isle Royale. They were photographed on the south shore of Lake Ojibway that November. Both had full stomachs, and one was carrying a dead beaver kit in its mouth. No beavers inhabited Lake Ojibway in 2018, or since that time.

Taking it from the top, wolves triggered a chain reaction that led to a four-year period of abundant aquatic vegetation in Lake Ojibway. Moose and beavers both took advantage of the forage. And when that forage was gone, both species shifted to forage on land. But when beavers made the shift (to terrestrial foraging), they put themselves at greater risk of wolf predation. Then the beavers of Lake Ojibway suffered a catastrophic failure of their dam-the beavers disappeared, and so too did much of Lake Ojibway. This, of course, is the story of just one lake. While every lake has its own story to tell, there is good reason to believe that most of those stories include wolves and their effect on moose, beavers, and the competitive foraging between moose and beavers.

\section{FINALLY, A WORD ABOUT RESTORING THE BALANCE}

In October 2021, Johns Hopkins University Press will release Restoring the Balance: What Wolves Tell Us about Our Relationship with Nature, a book by John A. Vucetich. Restoring the Balance combines the natural history of wolves and moose, the memoirs of a field biologist, and a clear-eyed exploration of environmental philosophy that emerges from thinking about wolves and our relationships with them. This book will be treasured by any thoughtful reader looking to deepen their relationship with nature and learn about the wolves of Isle Royale along the way. The treat is sweetened by a foreword written by David W. Macdonald, the world-renowned carnivore biologist from the University of Oxford, who said, "this exhilarating book is a ... remarkable triumph-beautifully crafted." 


\section{References}

1. Peterson, Vucetich, Fenton, Drummer, Larsen (2010) Ecology of arthritis. Ecology Letters 13, 1124-1128.

2. Vucetich, Outridge, Peterson, Eide, Isrenn (2009) Mercury, lead and lead isotope ratios in the teeth of moose (Alces alces) from Isle Royale, US Upper Midwest, from 1952 to 2002. Journal of Environmental Monitoring 11, $1352-1359$.

3. Hoy, Peterson, Vucetich (2018) Climate warming is associated with smaller body size and shorter lifespans in moose near their southern range limit. Global Change Biology 24, 2488-2497.

4. Vucetich (2021) Restoring the Balance. Johns Hopkins University Press.

5. Hedrick, Peterson, Vucetich, Adams, Vucetich (2014) Genetic rescue in Isle Royale wolves: genetic analysis and the collapse of the population. Conservation Genetics, 15, 1111-1121.

6. Montgomery, Vucetich, Peterson, Roloff, Millenbah (2013) The influence of winter severity, predation and senescence on moose habitat use. J. Animal Ecol 82, 301-309.

7. Bergman, Bump. 2015. Experimental evidence that the ecosystem effects of aquatic herbivory by moose and beaver may be contingent on water body type. Freshwater Biology 60, 1635-1646

Inside back cover: Photographs of watershield, a native aquatic plant, at Lake Ojibway in Isle Royale National Park in 2015-visible from a satellite (top), in the mouth of a feeding moose (middle), underwater (bottom left, photo by Joe Olenik), and on the surface of water (bottom right).

Back cover: Radio-collared bull \#40111 was a popular fixture for visitors at the Washington Creek Campground in August 2020.

18 | College of Forest Resources and Environmental Science 


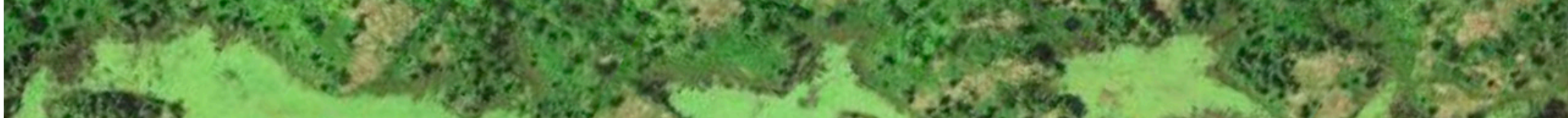

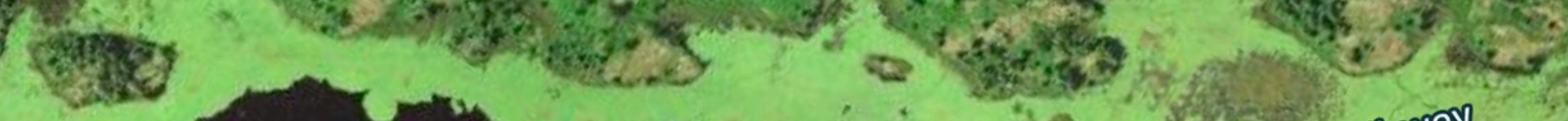

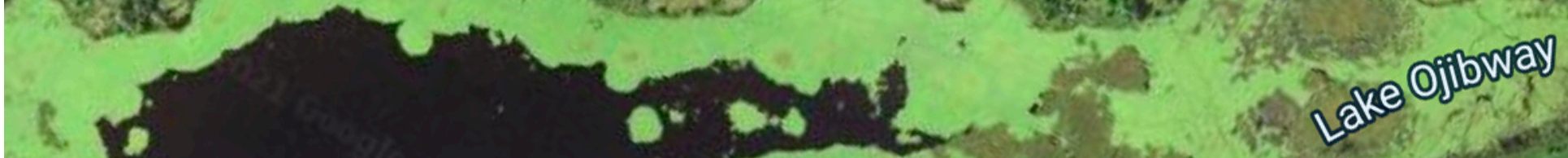

b. (19) Wrin

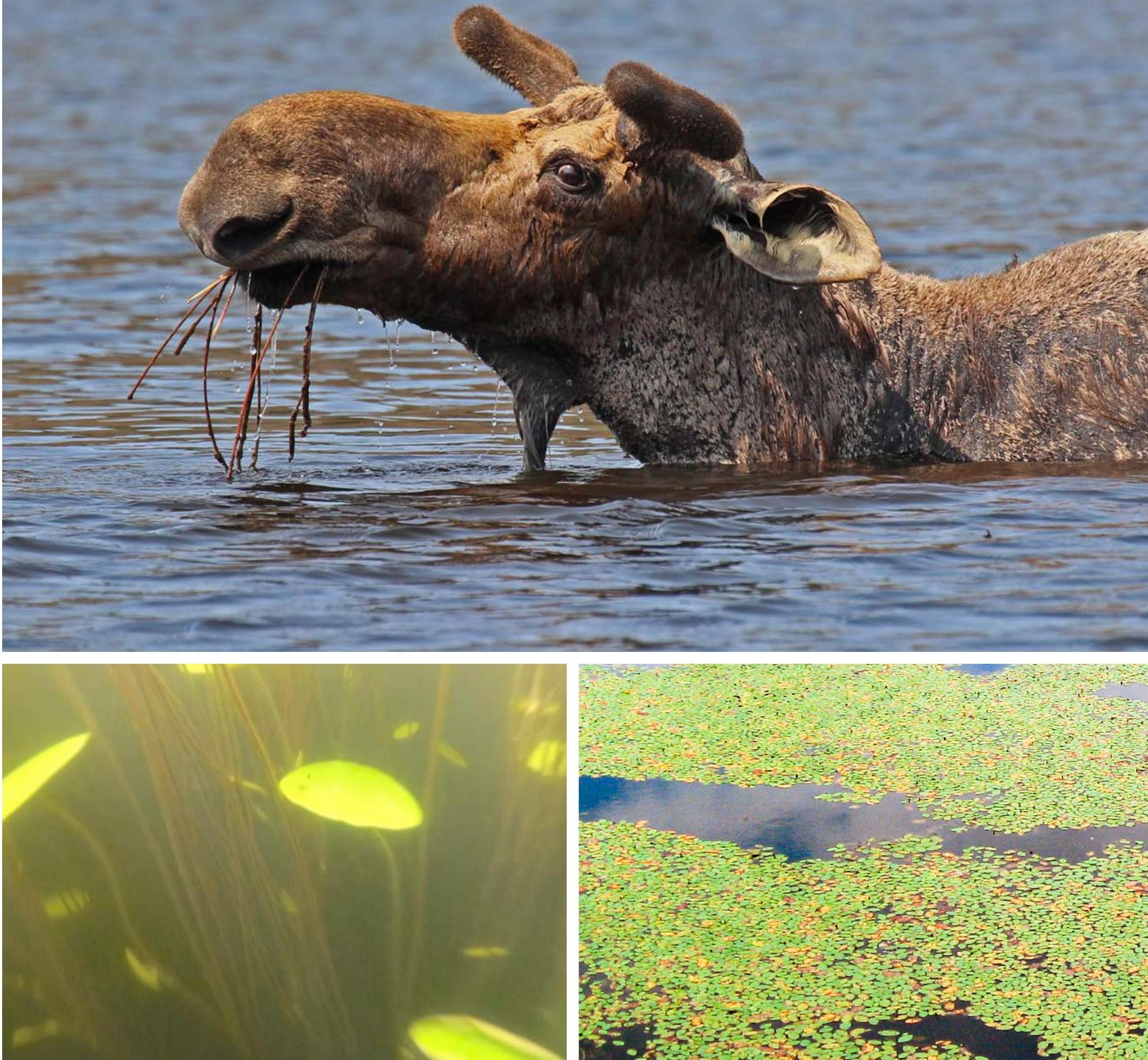


